\title{
THE IMMUNOGENICITY ERA - WHAT SHOULD WE KNOW ON ANTI-TNFS IN SPONDYLOARTHRITIS PATIENTS?
}

\author{
Claudia Deaconu ${ }^{1}$, Daniela Opris ${ }^{1,2}$, Ruxandra Ionescu ${ }^{1,2}$ \\ ${ }^{1}$ Department of Rheumatology and Internal Medicine, Sfanta Maria Clinical Hospital, Bucharest, Romania \\ ${ }^{2}$ Carol Davila University of Medicine and Pharmacy, Bucharest, Romania
}

\begin{abstract}
Spondyloarthritis $(\mathrm{SpA})$ patients do not respond uniformly to TNF inhibitor therapy, some of them losing their beneficial evolution and becoming primary or secondary non-responders. Hence, questions have been raised whether this situation is linked to predictive genetic factors, individual characteristics or to disease activity. Studies have incriminated immunogenicity as being responsible for the loss or lack of response. It appears that the development of anti-drug antibodies leads to a decrease in drug levels with further impact on patients' clinical state. This brief review aims to clarify some of the processes involved in the immunogenic phenomenon for patients with $\mathrm{SpA}$, based on the current published literature.
\end{abstract}

Keywords: spondyloarthritis, anti-TNF therapy, immunogenicity, anti-drug antibodies

\section{DATA ON THE IMMUNOGENICITY OF BIOLOGICAL AGENTS}

Introducing anti-TNF (tumor necrosis factor) therapy has significantly improved the outcome of patients with spondyloarthritis (SpA) by diminishing the clinical symptoms and lowering the global disease activity (1). In Romania, there are currently five approved anti-TNF agents-adalimumab (ADL), infliximab (IFX), etanercept (ETA), certolizumab (CTZ) and golimumab (GOL) (2).

In spite of a high rate of favorable response in 60$70 \%$ of patients, there is still a notable percentage of non-responders to biological therapy (3). Approximately one third of patients who initially had a good therapeutic evolution with TNF inhibitors lose this response or suffer from adverse reactions that lead to treatment discontinuation (4).

Although these products have a similar mechanism of action, the heterogeneity of response to these molecules can be attributed to certain differences in bioavailability, the drug-TNF complex stability or the development of anti-drug antibodies (5).

An increasing number of studies indicate that the lack or loss of response in SpA patients might be due to immune reactions against the drugs, by forming neutralizing antibodies. Immunogenicity to anti-
TNFs has been incriminated in the therapeutic failure in non-responder patients by lowering the level of active substance or in those with adverse events occurrence (6).

This feature is influenced by multiple factors and it differs according to the agent. Patient characteristics such as age, sex or weight can play a role in the immunogenic events (7). Moreover the structure of the drug, its dose and route of administration together with concomitant medication are elements worthy to be taken into account. The presence of anti-drug antibodies (ADA) shows a wide range of intra- and inter- individual variability (8).

The production of ADA is responsible for neutralizing the effect of TNF inhibitors or for increasing the clearance of the drug in the circulation, following the ulterior impact of therapy failure.

Cutaneous or respiratory reactions might be mediated by immune complexes formed between the drug and ADA which imposes drug discontinuation (9).

Monitoring drug serum level reveals its importance in patients who exhibit a loss of therapeutic response; in this case, clinicians can adjust the dose or frequency of administration. Therefore patients with a low drug serum level but with no detectable

Correspondence address:

Claudia Deaconu, Department of Rheumatology and Internal Medicine, Sf. Maria Clinical Hospital 37-39 Ion Mihalache Bd, District 1, Bucharest

E-mail: claudiadeaconu1@yahoo.com 
ADA can benefit from increasing the dose or frequency of the biologic $(8,10)$.

At present the two above-mentioned tests (drug serum level and ADA) are not routinely determined in clinical practice so that the decision to make a therapeutic switch is solely based on clinical data and laboratory parameters.

However in SpA patients where therapeutic options belong to the same anti-TNF category, objectifying the cause of loss of response seems to be a more rational approach for the management of these patients.

Neutralizing ADA directly block the action of the TNF inhibitor by linking to the Fab fragment of the immunoglobulin or they can occur secondary to structural alterations after binding to one or more agent sites. They can also form immune complexes that mask the TNF binding lieu. Thus these anti-idiotypic antibodies prevent the drug from acting which makes them clinically significant (11).

Non-neutralizing ADA can reduce the therapeutic efficacy by interfering with the drug's bioavailability or by accelerating the drug's clearance from the circulation (12).

\section{ADALIMUMAB AND ANTI-ADALIMUMAB ANTIBODIES}

Adalimumab (ADL) is a fully humanized monoclonal antibody that specifically binds to the TNF alpha and blocking its interaction to the cellular receptors, leading to reduction of the inflammatory process. In spite having a less immunogenic structure, ADL can induce ADA formation in the first six months of treatment with consequent therapeutic damage (13).

The presence of anti-ADL antibodies (AAA) varies in published studies, some suggesting an $87 \%$ rate in rheumatoid arthritis (RA). However, in RA using concomitant medication such as methotrexate (MTX) can reduce the rate of AAA production as opposed to the anti-TNF monotherapy that is recommended in SpA (8). In RA studies noted an increased production of AAA in patients who underwent a switch compared to biological naïve patients (14).

In inflammatory bowel diseases e.g. Crohn's disease the rate of AAA ranges from 9 to $46 \%$; in the CLASSICAL II trial, $2.6 \%$ of patients had positive AAA (15).

In these inflammatory conditions, the presence of AAA has been associated with a low or undetectable serum drug level and with a decreased probability of reaching remission or low disease activity (16).

Concerning the SpA group, AAA have been detected in $27 \%$ of patients and they were correlated to a higher disease activity measured through ASDAS and BASDAI scores but also through the inflammatory markers (17).

The presence of AAA can be related to adverse events, according to Korswagen et al. in 2011. He noticed a higher frequency of thromboembolic events in patients with RA or PsA with positive AAA (18).

\section{INFLIXIMAB AND ANTI-INFLIXIMAB ANTIBODIES}

Infliximab (IFX) is a chimeric monoclonal antibody with high affinity for both soluble and transmembrane TNF alpha; it has a ten day half time but it can remain in tissues for up to 12 weeks $(14,19)$. This molecule contains $25 \%$ murine sequences that can induce anti-IFX antibodies (AIA) that neutralize the active substance and reduce the beneficial effect. AIA can block the flow of the drug in the circulation, they can accelerate its clearance through immune complexes with splenic passage or they can neutralize its capacity to inhibit TNF (9).

As beforehand, the detection of AIA has been linked to an absent level of substance and a lower rate of remission in these patients. Medication such as methotrexate or azathioprine can reduce AIA formation but the mechanism is not fully understood.

AIA can be responsible for infusion-related adverse events that can occur after administration headaches, dyspnea, and nausea. So far ADA have not been connected to delayed hypersensitivity reactions (20).

In chronic inflammatory diseases the prevalence of AIA ranges from 12 to $44 \%$ in RA (21) and 6-61\% in Crohn patients (22). In the SpA group and PsA AIA can reach a rate of 26 to $50 \%$ (6). These rates are comparable to ADL's immunogenic profile despite their different structure (chimeric versus humanized).

For IFX the possibility to adjust the administration interval or the dose has been raised.

Hence, a study showed that shortening the interval of IFX reduces the level of AIA (15), while another study suggested the opposite $(14,19)$.

A minimal rise in efficacy has been attributed to the increase of biological dose in a study but this 
escalation showed no benefits in the presence of AIA in another study (19).

A meta-analysis published in 2015 which includes 34 studies with IFX estimates that the time of AIA detection is around 44-50 weeks although in some patients they were found after only 16 weeks of treatment (23).

\section{ETANERCEPT AND ANTI-ETANERCEPT ANTIBODIES}

Etanercept (ETA) is a soluble receptor for TNF composed from the fusion of the extracellular receptor domain with the Fc fragment of the IgG1 immunoglobulin (1).

In the same meta-analysis that we previously mentioned two studies searched for a AEA in patients with RA - one of them found no antibodies and the lack of response was due to low ETA levels (13).

The study conducted by Klareskog et al. 5\% of the RA patients were found having non-neutralizing AEA but with no clinical involvement (24).

In $\mathrm{SpA}$ patients there were no AEA detected so far and the ETA serum level was similar in both responders and non-responders (25).

A research published in 2014 identified a correlation between the ETA serum level and disease activity scores in SpA (ASDAS, BASDAI) as well as with inflammatory markers (ESR, CRP) (23). Thirty five percent of patients with an ASDAS higher than 2.1 at week 24 had low ETA levels (24). This determination can prove its utility in case of dose escalation with clinical benefits or cost-efficacy in patients with low disease activity where we can lower the dose or space administration. The outcome of these patients is still controversial and no algorithm has been established so far.

\section{CERTOLIZUMAB AND ANTI-CERTOLIZUMAB ANTIBODIES}

Certolizumab (CTZ) is a Fab fragment that specifically binds TNF alpha and it is conjugated with poly ethylene glycol (26).

The prevalence of anti-CTZ antibodies (ACA) is found to range between 3 and $25 \%$ in chronic inflammatory conditions. In the FAST4WARD study on RA patients in CTZ monotherapy after prior failure to DMARD treatment, $8.1 \%$ were identified with neutralizing ACA (27). However the ACR2 0 at week 24 was only reduced by $5 \%$ in patients with positive antibodies (27).
In patients with Crohn's disease, approximately $12 \%$ developed ACA but with doubtful clinical impact on efficacy according to the PRECISE study (8).

In the study of Reich et al. patients suffering from psoriasis treated with $\mathrm{CTZ}$ presented a higher rate of ACA detection after a period of drug interruption $(28,29)$.

\section{GOLIMUMAB AND ANTI-GOLIMUMAB ANTIBODIES}

Golimumab (GOL) is a humanized monoclonal antibody that binds to both soluble and transmembrane TNF alpha (30).

The frequency of anti-GOL antibodies (AGA) detection is situated between 0 and 7\% (31). Two studies held on RA and PsA patients failed to identify a correlation between the presence of AGA and the clinical response to treatment. However there has been a signaled connection between the presence of AGA and a low GOL serum level in patients with RA and $\operatorname{SpA}(1,23)$.

In the GO-RAISE study for SpA the responders had a higher GOL concentration compared to nonresponders. During the two years of the study, out of the $4.1 \%$ of patients who were AGA positive, half went negative after week 24 of therapy (30).

So far there were no associations made between the presence of AGA and side effects appearance.

\section{HOW CAN WE DETECT ANTI-DRUG ANTIBODIES?}

The classical methods for detecting ADA include the bridging ELISA (enzyme linked immunosorbent assay) technique and RIA (radioimmunoassay). The ELISA testing is sensitive and specific, relatively easy for wide use but it cannot detect type IgG4 antibodies, an isotype that occurs after prolonged immunization (20).

Binding the antigen technique uses radio isotopes that can identify type IgG1 and IgG4 antibodies with proven clinical significance but it is more expensive and uses radioactivity (32).

Some ADA detections can offer mistaken results caused by high concentrations of rheumatoid factor (RF) that mask the epitopes in the Fc region of the $\operatorname{IgG}(33)$.

A high drug concentration in the presence of ADA can lead to immune complex formation with 
fast product clearance together with in vivo ADA so their detection in vitro is made difficult.

At present newer and more rigorous techniques are being developed so that they can exclude these result biases. However they are more difficult to use in routine clinical practice. The ADA prevalence that varies a lot between studies depends on the type of procedure so that comparing biolgics or even the same product is to some extent difficult.

Although the immunogenicity phenomenon is not fully understood, instruments for predicting its occurrence both in vivo and vitro are being developed so that this effect can be further minimized (34). American and European drug control associations have imposed testing immune reactions induced by monoclonal antibodies before approving them for use.

\section{WHAT FACTORS INFLUENCE THE IMMUNOGENICITY OF TNF BLOCKERS?}

There are numerous factors involved in modulating the immunogenicity phenomenon of anti-TNF agents. Firstly, those that depend on the ADA detection method - the technique, the moment of blood draw or the duration of treatment (20). There are also factors that depend on the product itself, like a contamination during the preparation process, the structural properties or the murine component included in the agent's sequence (35).

Moreover the immunogenicity can depend on individual patient characteristics, his genetic predisposition or the immunocompetent status (36).

Regarding the treatment, the dose and frequency of administration, the route of administration or concomitant use of immunomodulating drugs can induce immunogenic qualities to the biologic agents (37).

\section{WHEN IS THE OPTIMAL TIME TO DETECT ANTI-DRUG ANTIBODIES?}

Optimal testing for ADA detection is performed at the end of a therapeutic cycle when we can detect the "trough level" (7). This is the preferred method since most tests cannot accurately detect serum ADA close to the drug administration point. In daily practice there are situations that influence this analysis e.g. long treatment discontinuation.

Determining ADA trough levels after a treatment pause can result in higher than expected values through intensifying the immune response (14).
The clinician can decide a shorter administration interval of the TNF inhibitor when faced to an apparent therapeutic failure. Determining ADA can give lower than expected results by the rapid elimination of the drug-ADA structures from the circulation (38).

Controlling these result biases can be made by dividing the drug-antibody complexes before or during the detection tests but these are difficult to adapt to daily clinical routine.

\section{HOW CAN WE CONTROL BIOLOGICS' IMMUNOGENICITY?}

Secondary non-responders are patients who lose their initial benefit from anti-TNF therapy and this state can be attributed to ADA formation. Their identification is not part of the routine investigations so that the cause of treatment failure remains unclear for the clinicians.

Concomitant use of medications such as methotrexate or azathioprine has been associated with lower immunogenicity and a lower rate of ADA detection in RA, SpA and Crohn's disease (39).

Studies have shown that the use of methotrexate can reduce the immunogenic profile of IFX and ADL to $41 \%$ by blocking the expansion of $\mathrm{T}$ and $\mathrm{B}$ lymphocytes with further modulation of the immune response (40). Other studies suggest a supplementary action on the inflammatory process, with its synergic reduction. Thus, a higher concentration of active substance would be available (39).

A rational question would be if including MTX in the treatment of SpA patients as part of the combotherapy would influence the immunogenic events and improve the therapeutic effect, especially in SpA where therapeutic options are limited compared to RA.

So far using MTX with IFX in SpA has offered debatable results, while a double blind randomized study with GOL plus MTX showed no significant results, probably due to low ADA positive (41).

Azathioprine has been evaluated together with TNF blockers in Crohn's disease where it showed a reduction of ADA formation (36).

Adding immunosuppressive therapy to biologic agents for the treatment of SpA, RA or Crohn's disease has not been associated with a higher risk of adverse events.

Other molecules such as leflunomide have no convincing data on this topic (36). 
Using glucocorticoids as intravenous hydrocortisone can reduce the level of AIA in patients with Crohn's disease but it cannot prevent their formation or infusion-related events. Future studies should include pre-medication that can limit damaging immune reactions (42).

Certain studies indicate that a low serum level of TNF inhibitor is associated with the presence of ADA in the case of non-responders, issuing the hypothesis that a low dose of biologic allows ADA formation while high doses of anti-TNF block this effect. This theory has been proven for IFX in SpA and Gottlieb et al. showed a higher frequency of ADA in patients with psoriasis receiving $3 \mathrm{mg} / \mathrm{kg}$ versus those with $5 \mathrm{mg} / \mathrm{kg}$ (43).

In addition, spacing the administration of antiTNF can stimulate ADA production in patients with clinical remission. The fact that the IFX treatment scheme that follows the protocol is more beneficial than an "on demand" regime stands to support this idea. Besides, the latter can produce a threefold increase in the risk of adverse reactions (33).

\section{WHAT RESULTS CAN WE EXPECT WHEN TESTING FOR ANTI-DRUG ANTIBODIES?}

When determining anti-TNF serum level and anti-drug antibodies there are four expected result categories (44):

- Loss of response when there is a sub-therapeutic drug level and negative ADA. This result can be due to an inadequate bioavailability or a disturbance in the drug pharmacokinetics, with an increased turnover. This can be caused by a high level of inflammation with excessive TNF amounts in the affected tissues or in patients with inflammatory enteral disorders that lead to drug elimination. Patients in this category can benefit from intensifying antiTNF therapy and they do not need a change of therapy.

- Loss of response in the context of moderate or high capacity to block circulating TNF. This can be encountered when there are new immune-inflammatory pathways that avoid TNF. These patients need a switch on another TNF inhibitor or another therapeutic class, the latter being unavailable in SpA patients in our country.

- Loss of response in the presence of neutralizing ADA and inadequate neutralize of TNF with or without increased drug clearance. These ADA are specific to the administered drug and for this reason it is recommended to switch the anti-TNF molecule.

- Loss of response while having an optimal drug level and detectable ADA is a relatively rare situation and it can be met in case of false positive results. For these patients, a second determination is recommended; if the same result is given it suggests an anomaly of the product's pharmacodynamics.

Taking into account the current literature data, regularly monitoring the drug serum level together with detecting the presence of anti-drug antibodies might improve the therapeutic strategy of biologics in patients with SpA by guiding clinicians' decision to a more targeted approach. The future concept of personalized medicine will allow us to make safe and cost-effective choices for patients, based on objective and rigorous analysis.

\section{REFERENCES}

1. L.J. Maxwell, J. Zochling, A. Boonen, J. A. Singh, M.M.S. Veras, E. Tanjong Ghogomu, M. Benkhalti Jandu, P. Tugwell, G. A. Wells, TNF-alpha inhibitors for ankylosing spondylitis, Cochrane database Syst. Rev., vol. 4, p. CD005468, Jan. 2015.

2. J. Sieper, Developments in therapies for spondyloarthritis, Nat. Rev. Rheumatol., vol. 8, no. 5, pp. 280-7, May 2012.

3. J.S. Smolen, J. Braun, M. Dougados, P. Emery, O. et al, Treating spondyloarthritis, including ankylosing spondylitis and psoriatic arthritis, to target: recommendations of an international task force, Ann. Rheum. Dis., vol. 73, no. 1, pp. 6-16, Jan. 2014.

4. S. Arends, H.R. Lebbink, A. Spoorenberg, L.B. et al. The formation of autoantibodies and antibodies to TNF- $\alpha$ blocking agents in relation to clinical response in patients with ankylosing spondylitis, Clin. Exp. Rheumatol., vol. 28, no. 5, pp. 661-8.

5. R.A. Farrell, M. Marta, A.J. Gaeguta, et al. Development of resistance to biologic therapies with reference to IFN- $\beta$, Rheumatology (Oxford), vol. 51, no. 4, pp. 590-9, Apr. 2012.

6. S. Garcês, J. Demengeot, E. Benito-Garcia, The immunogenicity of anti-TNF therapy in immune-mediated inflammatory diseases: a systematic review of the literature with a meta-analysis, Ann. Rheum. Dis., vol. 72, no. 12, pp. 1947-55, Dec. 2013.

7. M. Svenson, P. Geborek, T. Saxne, K. Bendtzen, Monitoring patients treated with anti-TNF-alpha biopharmaceuticals: assessing serum infliximab and anti-infliximab antibodies, Rheumatology (Oxford), vol. 46, no. 12, pp. 1828-34, Dec. 2007.

8. D. Mazilu, D. Opriş, C. Gainaru, M. Iliuta, N. Apetrei, G. Luca, A. Borangiu, T. Gudu, A. Peltea, L. Groseanu, C. Constantinescu, I. Saulescu, V. Bojinca, A. Balanescu, D. Predeteanu, R. lonescu, Monitoring drug and antidrug levels: a rational approach in rheumatoid arthritis patients treated with biologic agents who experience inadequate response while being on a stable biologic treatment, Biomed Res. Int., vol. 2014, p. 702701, Jan. 2014.

9. D. van der Heijde, B. Dijkmans, P. Geusens, J. Sieper, K. DeWoody, P. Williamson, J. Braun, Efficacy and safety of 
infliximab in patients with ankylosing spondylitis: results of a randomized, placebo-controlled trial (ASSERT), Arthritis Rheum, vol. 52, no. 2, pp. 582-91, Feb. 2005.

10. K. Bendtzen, Immunogenicity of Anti-TNF-a Biotherapies: I. Individualized Medicine Based on Immunopharmacological Evidence, Front. Immunol., vol. 6, p. 152, Apr. 2015.

11. F.B. Vincent, E.F. Morand, K. Murphy, F. Mackay, X. Mariette, C. Marcelli, Antidrug antibodies (ADAb) to tumour necrosis factor (TNF)-specific neutralising agents in chronic inflammatory diseases: a real issue, a clinical perspective, Ann. Rheum. Dis., vol. 72, no. 2, pp. 165-178, Feb. 2013.

12. J.R. Maneiro, E. Salgado, J.J. Gomez-Reino, Immunogenicity of monoclonal antibodies against tumor necrosis factor used in chronic immune-mediated Inflammatory conditions: systematic review and meta-analysis, JAMA Intern. Med., vol. 173, no. 15, pp. 1416-28, Aug. 2013.

13. F. Atzeni, R. Talotta, F. Salaffi, A. Cassinotti, V. Varisco, M. Battellino, S. Ardizzone, F. Pace, P. Sarzi-Puttini, Immunogenicity and autoimmunity during anti-TNF therapy, Autoimmun. Rev., vol. 12, no. 7, pp. 703-708, 2013.

14. A. van der Maas, B.J.F. van den Bemt, G. Wolbink, F.H.J. van den Hoogen, P.L.C.M. van Riel, A.A. den Broeder, Low infliximab serum trough levels and anti-infliximab antibodies are prevalent in rheumatoid arthritis patients treated with infliximab in daily clinical practice: results of an observational cohort study, BMC Musculoskelet. Disord., vol. 13, no. 1, p. 184, Jan. 2012.

15. W. Afif, E.V. Loftus, W.A. Faubion, S.V. Kane, D.H. Bruining, K.A. Hanson, W.J. Sandborn, Clinical utility of measuring infliximab and human anti-chimeric antibody concentrations in patients with inflammatory bowel disease, Am. J. Gastroenterol, vol. 105, no. 5, pp. 1133-9, May 2010.

16. P.L. Meroni, G. Valentini, F. Ayala, A. Cattaneo, G. Valesini, New strategies to address the pharmacodynamics and pharmacokinetics of tumor necrosis factor (TNF) inhibitors: A systematic analysis, Autoimmun. Rev., vol. 14, no. 9, pp. 812-829, 2015.

17. E.L. Kneepkens, J.C.-C. Wei, M.T. Nurmohamed, K.J. Yeo, C.Y. Chen, I. E. van der Horst-Bruinsma, D. van der Kleij, T. Rispens, G. Wolbink, C.L.M. Krieckaert, Immunogenicity, adalimumab levels and clinical response in ankylosing spondylitis patients during 24 weeks of follow-up, Ann. Rheum. Dis., vol. 74, no. 2, pp. 396-401, Mar. 2015.

18. L.A. Korswagen, G.M. Bartelds, C.L.M. Krieckaert, F. Turkstra, M.T. Nurmohamed, D. van Schaardenburg, C.A. Wijbrandts, P. P. Tak, W. F. Lems, B.A.C. Dijkmans, R.M. van Vugt, G.J. Wolbink, Venous and arterial thromboembolic events in adalimumab-treated patients with antiadalimumab antibodies: a case series and cohort study, Arthritis Rheum., vol. 63, no. 4, pp. 877-83, Apr. 2011

19. M.K. de Vries, G.J. Wolbink, S.O. Stapel, H. de Vrieze, J.C. van Denderen, B.A.C. Dijkmans, L.A. Aarden, I.E. van der HorstBruinsma, Decreased clinical response to infliximab in ankylosing spondylitis is correlated with anti-infliximab formation, Ann. Rheum. Dis., vol. 66, no. 9, pp. 1252-4, Sep. 2007

20. B.D. Hock, L.K. Stamp, M.W. Hayman, P.E. Keating, E.T.J. Helms, M.L. Barclay, Development of an ELISA based competitive binding assay for the analysis of drug concentration and anti-drug antibody levels in patients receiving adalimumab or infliximab, Ther. Drug Monit., Jul. 2015.

21. B.J.F. van den Bemt, A.A. den Broeder, G.F. Snijders, Y.A. Hekster, P.L.C.M. van Riel, B. Benraad, G.J. Wolbink, F.H.J. van den Hoogen, Sustained effect after lowering high-dose infliximab in patients with rheumatoid arthritis: a prospective dose titration study, Ann. Rheum. Dis., vol. 67, no. 12, pp. 1697-1701, Dec. 2008.

22. S.B. Hanauer, C.L. Wagner, M. Bala, L. Mayer, S. Travers, R.H. Diamond, A. Olson, W. Bao, P. Rutgeerts, Incidence and importance of antibody responses to infliximab after maintenance or episodic treatment in Crohn's disease, Clin. Gastroenterol. Hepatol., vol. 2, no. 7, pp. 542-553, 2004.

23. S.S. Thomas, N. Borazan, N. Barroso, L. Duan, S. Taroumian, B. Kretzmann, R. Bardales, D. Elashoff, S. Vangala, D.E. Furst, Comparative Immunogenicity of TNF Inhibitors: Impact on Clinical Efficacy and Tolerability in the Management of Autoimmune Diseases. A Systematic Review and Meta-Analysis, Bio Drugs, vol. 29, no. 4, pp. 241-58, Aug. 2015.
24. E.L. Kneepkens, C.L. M. Krieckaert, D. van der Kleij, M.T. Nurmohamed, I.E. van der Horst-Bruinsma, T. Rispens, G.J. Wolbink, Lower etanercept levels are associated with high disease activity in ankylosing spondylitis patients at 24 weeks of follow-up, Ann. Rheum. Dis., vol. 74, no. 10, pp. 1825-9, Oct. 2015

25. I.H. Song, K. Hermann, H. Haibel, C. E. Althoff, C. Althoff, J. Listing, G. Burmester, A. Krause, M. Bohl-Bühler, B. Freundlich, M. Rudwaleit, J. Sieper, Effects of etanercept versus sulfasalazine in early axial spondyloarthritis on active inflammatory lesions as detected by whole-body MRI (ESTHER): a 48-week randomised controlled trial, Ann. Rheum. Dis., vol. 70, no. 4, pp. 590-6, Apr. 2011.

26. S. V Faraone, Interpreting estimates of treatment effects: implications for managed care, $P T$, vol. 33, no. 12, pp. 700-11, Dec. 2008

27. R. Fleischmann, J. Vencovsky, R.F. van Vollenhoven, D. Borenstein, J. Box, G. Coteur, N. Goel, H.P. Brezinschek, A. Innes, V. Strand, Efficacy and safety of certolizumab pegol monotherapy every 4 weeks in patients with rheumatoid arthritis failing previous disease-modifying antirheumatic therapy: the FAST4WARD study, Ann. Rheum. Dis., vol. 68, no. 6, pp. 805-11, Jun. 2009.

28. C. Steenholdt, M. Al-khalaf, J. Brynskov, K. Bendtzen, O. Thomsen, M.A. Ainsworth, Clinical implications of variations in anti-infliximab antibody levels in patients with inflammatory bowel disease, Inflamm. Bowel Dis., vol. 18, no. 12, pp. 2209-2217, Dec. 2012

29. P.A. van Schouwenburg, L.A. van de Stadt, R.N. de Jong, E.E. L. van Buren, S. Kruithof, E. de Groot, M. Hart, S.M. van Ham, T. Rispens, L. Aarden, G.J. Wolbink, D. Wouters, Adalimumab elicits a restricted anti-idiotypic antibody response in autoimmune patients resulting in functional neutralisation, Ann. Rheum. Dis., vol. 72, no. 1, pp. 104-109, Jan. 2013.

30. A. Deodhar, J. Braun, R.D. Inman, D. van der Heijde, Y. Zhou, S. Xu, C. Han, B. Hsu, Golimumab administered subcutaneously every 4 weeks in ankylosing spondylitis: 5 -year results of the GORAISE study, Ann. Rheum. Dis., vol. 74, no. 4, pp. 757-61, Apr. 2015

31. V. Calvo-Río, R. Blanco, M. Santos-Gómez, E. Rubio-Romero, M. Cordero-Coma, A. Gallego-Flores, R. Veroz, I. Torre, F.F. Hernández, A. Atanes, J. Loricera, M.C. González-Vela, N. Palmou, J.L. Hernández, M.A. González-Gay, Golimumab in refractory uveitis related to spondyloarthritis. Multicenter study of 15 patients, Semin. Arthritis Rheum., Mar. 2016.

32. K. Bendtzen, Immunogenicity of Anti-TNF-a Biotherapies: II. Clinical Relevance of Methods Used for Anti-Drug Antibody Detection, Front. Immunol., vol. 6, p. 109, 2015.

33. F.B. Vincent, E.F. Morand, K. Murphy, F. Mackay, X. Mariette, and $\mathrm{C}$. Marcelli, Antidrug antibodies (ADAb) to tumour necrosis factor (TNF)-specific neutralising agents in chronic inflammatory diseases: a real issue, a clinical perspective, Ann. Rheum. Dis., vol. 72, no. 2, pp. 165-78, Feb. 2013.

34. B. Schlain, L. Amaravadi, J. Donley, A. Wickramasekera, D. Bennett, M. Subramanyam, A novel gamma-fitting statistical method for anti-drug antibody assays to establish assay cut points for data with non-normal distribution, J. Immunol. Methods, vol. 352, no. 1-2, pp. 161-8, Jan. 2010.

35. General introduction.

36. M. Deehan, S. Garcês, D. Kramer, M. P. Baker, D. Rat, Y. Roettger, A. Kromminga, Managing unwanted immunogenicity of biologicals, Autoimmun. Rev., vol. 14, no. 7, pp. 569-574, 2015.

37. C.A. Weber, P.J. Mehta, M. Ardito, L. Moise, B. Martin, A.S. De Groot, T cell epitope: Friend or Foe? Immunogenicity of biologics in context, Adv. Drug Deliv. Rev.

38. M. Lorenzin, A. Ortolan, M. de Hooge, P. Frallonardo, A. Piccoli, F. Cozzi, F. Oliviero, L. Punzi, R. Ramonda, Lengthening the time intervals between doses of biological agents in psoriatic arthritis patients: A single-center retrospective study, Int. J. Immunopathol. Pharmacol., vol. 28, no. 4, pp. 479-87, Dec. 2015.

39. M. Jani, A. Barton, R.B. Warren, C.E.M. Griffiths, H. Chinoy, The role of DMARDs in reducing the immunogenicity of TNF inhibitors in chronic inflammatory diseases, Rheumatology (Oxford)., vol. 53, no. 2, pp. 213-22, Feb. 2014. 
40. S.Z. Aydin, M. Can, P. Atagunduz, H. Direskeneli, Active disease requiring TNF-alpha-antagonist therapy can be well discriminated with different ASDAS sets: a prospective, follow-up of disease activity assessment in ankylosing spondylitis, Clin. Exp. Rheumatol., vol. 28, no. 5, pp. 752-5, Jan. .

41. M. Jani, H. Chinoy, R.B. Warren, C. EM Griffiths, D. Plant, B. Fu, A.W. Morgan, A.G. Wilson, J.D. Isaacs, K.L. Hyrich, A. Barton, Clinical utility of random anti-TNF drug level testing and measurement of anti-drug antibodies on long-term treatment response in rheumatoid arthritis, Arthritis Rheumatol., vol. 67, no. 8 , p. n/a-n/a, Apr. 2015.
42. R.J. Farrell, M. Alsahli, Y.T. Jeen, K.R. Falchuk, M.A. Peppercorn, P. Michetti, S. Targan, W. Arnold, Intravenous hydrocortisone premedication reduces antibodies to infliximab in Crohn's disease: A randomized controlled trial, Gastroenterology, vol. 124, no. 4, pp. 917-924, Apr. 2003.

43. L. Hsu, A.W. Armstrong, Anti-drug antibodies in psoriasis: a critical evaluation of clinical significance and impact on treatment response, Expert Rev. Clin. Immunol., vol. 9, no. 10, pp. 949-58, Oct. 2013

44. N. Kulagina, L. Kelly, Overcoming False Positive Response in Anti-Drug Antibody Method, 2014. 